\title{
Asthma Patient Care: The Pharmacist's Perspective
}

\author{
Rana Rasheed Farrag1*, Mamdouh Ahmed Zaki1, Taher El-Naggar², Manal El-Hamamsy ${ }^{3}$ \\ ${ }^{1}$ Department of Clinical Pharmacy and Pharmacy Practice, Faculty of Pharmacy, Ahram Canadian University \\ (ACU), 6th of October City, Egypt \\ ${ }^{2}$ Department of Chest Diseases, Faculty of Medicine, Ain Shams University (ASU), Cairo, Egypt \\ ${ }^{3}$ Department of Clinical Pharmacy, Faculty of Pharmacy, Ain Shams University (ASU), Cairo, Egypt \\ Email: rana rasheed86@yahoo.com
}

Received 13 February 2014; revised 11 May 2014; accepted 28 May 2014

Copyright (C) 2014 by authors and Scientific Research Publishing Inc.

This work is licensed under the Creative Commons Attribution International License (CC BY). http://creativecommons.org/licenses/by/4.0/

(c) (i) Open Access

\begin{abstract}
Aim of the Study: To compare effect of asthma care by pharmacist intervention versus routine care on asthma control. Patients and Methods: A 2-month randomised, controlled trial was conducted in outpatient clinics of Ain Shams University Hospitals, Cairo, Egypt. Patients were randomly assigned to receive routine care or a pre-defined pharmacist intervention. This intervention was mainly focused on patient education, improving inhalation technique and medication assessment. Primary outcome was the level of asthma control, as assessed by the Asthma Control Questionnaire (ACQ). Results: By the end of the study, intervention patients who received a written action plan significantly improved their ACQ results than routine care group who did not receive a plan (p < 0.0001). Inhalation technique and adherence to controller medication were significantly better in the intervention group. Conclusion: The present study results provide supportive evidence concerning pharmacists' favourable effects on asthma patient care and support pharmacists as valuable members of the health care team.
\end{abstract}

\section{Keywords}

Asthma Control Questionnaire, Asthma Action Plan, Patient Education, Adherence, Inhalation Technique

\section{Introduction}

Asthma is an "inflammatory disorder of the airways characterized by paroxysmal or persistent symptoms such

${ }^{*}$ Corresponding author. 
as dyspnea, chest tightness, wheezing, sputum production and cough, associated with variable airflow limitation and a variable degree of hyper-responsiveness of airways to endogenous or exogenous stimuli” [1].

Asthma is a common chronic disorder with increased prevalence worldwide [2]. World Health Organization (WHO) estimates that 235 million people currently suffer from asthma. Asthma occurs in all countries regardless of the level of development. However, most asthma-related deaths occur in low- and lower-middle income countries [3].

Asthma is a non-curable disease but it can be controlled [3]. Although good asthma control can be achieved in clinical trials, it is more difficult to achieve in "real-life situation studies" [4]. Despite advances in asthma management, a large number of patients are still "insufficiently controlled", putting them "at risk for asthma-related morbidity and mortality" [5].

Salama and his colleagues reported that "health care delivery was inadequate in Egypt as irrational prescribing and practices were generally widespread and misconceptions were commonly encountered, both among the public and health professionals". Thus, there is an urgent need to identify standards of health care for individuals with asthma [6].

The Global Initiative for Asthma (GINA) updated its asthma management guidelines (GINA 2012) and now emphasizes asthma management based on clinical control rather than on asthma severity [7]. Assessing control of asthma should include both impairment and risk domains [8]. In such a perspective, control of the disease is achieved through optimal symptom control with minimal functional limitations, and decreasing the likelihood of asthma exacerbation as well [9]. Asthma exacerbations can increase health care use and affect quality of life of the patient; moreover, it may lead to severe life-threatening episodes, and promote loss of pulmonary function [10]. Achievement and maintenance of asthma control can be obtained through patient education, adequate assessment of control including objective measures of airway function, environmental measures, adapted pharmacotherapy and regular follow-up [11].

Pharmacists could assist asthma patients and their physicians to achieve and maintain asthma control by providing the patient with suitable information and training about asthma medication, instructing correct inhalation technique, questioning the patient's understanding of the role of their asthma medications, explaining why inhaled corticosteroids are necessary, addressing the patient's concerns about potential side-effects of inhaled corticosteroids and facilitating adherence to controller medication. These factors have already been shown to be important barriers to the achievement of good asthma control [12] [13].

Proper patient education was emphasized in all recent guidelines to provide patients with the skills necessary to control asthma and improve its outcome. Such intervention provided by pharmacist is feasible and merits further studies of effectiveness [1] [7] [8] [14].

\section{Patients and Methods}

\subsection{Patients}

Eighty Asthma patients were recruited consecutively from the outpatient clinics of Ain Shams University Hospitals, Cairo, Egypt. Adult patients (18 - 70 years) with clinical diagnosis of asthma were invited to participate in the study provided that they are responsible for administering their own asthma medications.

Patients were excluded from the study if they were not responsible for administering their own asthma medications, suffering from cognitive defects, other pulmonary disease e.g. Chronic Obstructive Pulmonary Disease (COPD), experiencing illness with asthma-like symptoms e.g. Congestive Heart Failure, evidence of fixed airway obstruction, unavailable for 2-month follow-up, or did not provide written informed consent.

\subsection{Study Design}

This study was designed as a 2-month randomized, controlled, parallel group trial. It was carried out between March 2012 and January 2013 (patient recruitment period: March-November 2012). The study was performed in accordance with the principles of Declaration of Helsinki and its appendices [15]. Approval was obtained from the research ethics committee at Ain Shams University, and written informed consent was obtained for all cases.

Patients, who agreed to participate in this study, had a 1-week run-in period to evaluate their asthma symptoms and perform spirometry. Sixty eligible patients were randomly assigned to either intervention group (integrated pharmaceutical care, $n=30)$ or routine care group $(n=30)$ with the aid of Random Allocation Software 
(version 1.0.0). At baseline, each patient provided his/her personal information, asthma history in patient data record, answered asthma control questionnaire, and underwent spirometry to measure his/her forced expiratory volume in 1 second (FEV1).

\subsection{Intervention}

Patients in the intervention group received a protocol-defined intervention at the start of the study and lasted over a 2-month follow-up period while patients in the routine care group received usual care as an active comparator. Patients in the pharmacist-intervention group received additional education by pharmacist on basic facts about asthma, role of medications, the difference between long-term control medications and quick-relief medication, as well as patient skills in the first visit then reinforcement every two weeks. The importance of proper inhaler technique, avoidance of asthma triggers and self-monitoring of asthma were also highlighted. Visual aids, as well as written information resources in patient's own language were supplied. Proper inhaler technique was physically demonstrated to the patient and the patient was asked to return the demonstration. Assessment of inhaler technique was repeated at each follow-up visit. Written asthma action plans were also provided. These asthma action plans were tailored to patient needs and preferences to provide shared decision making and facilitate adherence. Patients were informed how to detect early signs of worsening asthma, when and how to seek medical care as appropriate.

Patients in the routine care group received usual care delivered by physician without pharmacist intervention. They were prescribed asthma medication with summarized basic information on asthma and medication use. Follow-up visits were not planned on consistent basis, but rather individually according to the disease status. No asthma action plans were provided.

Patients from both groups were required to answer asthma control questionnaire and perform spirometry to measure Forced Expiratory Volume in 1 second (FEV1) at baseline and after 2 months for study purposes.

To summarize differences in methods for delivery of care between both groups: First, the intervention group received patient education and medication evaluation by pharmacist based on recent GINA recommendations [7], while routine care group received usual medical care by physician. Second, patient education in the pharmacistintervention group was concerned with basic facts about asthma, role of medication as well as important patient skills and self-management (proper inhalation technique, use of written asthma action plans, identification and avoidance of asthma triggers, and how to seek medical care as appropriate) while patients in routine care group did not receive specialized education on effectively developing patient skills. Third, specialized tools (e.g. asthma control questionnaire score, written asthma action plan and proper inhaler technique checklists) were used on consistent basis to evaluate asthma control status and guide treatment decisions in the pharmacist-intervention group but this was not the case in the routine care group where patients did not receive written asthma action plans but asthma control questionnaire and proper inhaler technique checklist were used for study purposes. Fourth, the importance of follow-up visits was more emphasized in the pharmacist-intervention group. Follow up visits were scheduled every two weeks for duration of two months to evaluate asthma medication, reinforce patient education, address patient concerns about asthma and its medication, and referral to physician if the patient case implies.

\subsection{Outcomes}

The primary endpoint was a comparison of the difference in change in the Asthma Control Questionnaire (ACQ)scores from baseline to 2 months between intervention and routine care. The ACQ is a validated tool that incorporates both objective and subjective measures of asthma control. Patients are asked to recall their symptoms and short-acting $\beta_{2}$-agonist use during the previous week. The most important symptoms used by clinician for assessing asthma control are included in the questionnaire. These syptoms are incorporated in the first five questions on night symptoms, limitation of normal daily activities, morning symptoms, dyspnea and wheeze. In addition, there is a question on short-acting $\beta_{2}$-agonist use and another one on FEV1 \% predicted, with information for the latter being provided by the clinic staff [16]. All seven questions are scored on a 7-point scale $(0=$ good control, 6 = poor control) and the overall score is the mean of the seven responses [16]. ACQ-scores equal to or less than 0.75 indicates well-controlled asthma while scores equal to or greater than 1.5 indicates not well-controlled asthma. ACQ-scores of 0.76 - 1.4 are indeterminate regarding well-controlled asthma [8].

Secondary endpoints included the comparisons of the following parameters: FEV1 (at baseline and after two 
months of therapy); inhaled corticosteroid use (at baseline and after two months of therapy); quick-relief medication use (at baseline and after two months of therapy); number of courses of oral steroid; the number of ER visits and asthma-related hospitalizations. Inhaled corticosteroid use is compared as number of puffs of beclomethasone equivalents based on health care guideline on diagnosis and management of asthma issued by Institute for Clinical Systems Improvement in 2012 [17]. Other end points were assessment of inhalation technique and adherence to therapy between the intervention and routine care groups.

\subsection{Statistical Analysis}

All data was presented on specially designed spreadsheet, verified and then encoded prior to analysis. IBM SPSS statistics (Version 21.0, IBM Corporation, USA, 2012) was used for data analysis. Data were expressed as Mean and Standard Deviation (SD) for quantitative parametric measures, Median and Percentiles for quantitative non-parametric measures in addition to both number and percentage for categorical data. The following tests were done:

1. Comparison between two independent groups for parametric data using $t$ test.

2. Comparison between two independent groups for non-parametric data using Wilcoxon Rank Sum test.

3. Chi-square test to study the association between each two variables or comparison between two independent groups as regards the categorical data.

A p-value equal to or below 0.05 was considered to be statistically significant.

\section{Results}

A total of sixty patients completed the study. The intervention group was represented by 24 females (80\%) and 6 males (20\%), while the routine care group was represented by 22 females (73.3\%) and 8 males (26.7\%). Demographic and clinical characteristics for both groups are summarized in Table 1 \& Table 2, Baseline line characteristics for intervention and routine care groups were well matched except for FEV1 \% (of predicted). Therefore, calculation of delta change was used as basis for comparison for both Asthma Control Questionnaire (ACQ) score and FEV1 as a more conservative strategy for comparing asymmetric data. Clinical characteristic for patients completed the study are summarized in Table 3.

\subsection{Asthma Control}

Both study groups showed improvement in Asthma Control Questionnaire (ACQ) score after a 2-month follow-

\begin{tabular}{|c|c|c|c|c|}
\hline Variable & $\begin{array}{c}\text { Intervention Group } \\
\mathrm{n}=30\end{array}$ & $\begin{array}{c}\text { Routine Care Group } \\
\mathrm{n}=30\end{array}$ & p-value & Sig. \\
\hline \multicolumn{5}{|l|}{ Gender n (\%) ${ }^{a}$} \\
\hline Male & $6(20)$ & $8(26.7)$ & \multirow[t]{2}{*}{0.542} & \multirow[t]{2}{*}{ NS } \\
\hline Female & $24(80)$ & $22(73.3)$ & & \\
\hline $\begin{array}{l}\text { Age in Years } \\
\text { Mean } \pm \mathrm{SD} \text { (range) }\end{array}$ & $\begin{array}{l}40 \pm 12.7 \\
(19-68)\end{array}$ & $\begin{array}{l}40 \pm 13.1 \\
(18-63)\end{array}$ & 0.982 & NS \\
\hline \multicolumn{5}{|l|}{ Education n (\%) ${ }^{a}$} \\
\hline No High School Degree & $12(40)$ & $13(43.3)$ & \multirow{3}{*}{0.849} & \multirow{3}{*}{ NS } \\
\hline High School Degree & $15(50)$ & $13(43.3)$ & & \\
\hline Higher Education $\$$ & $3(10)$ & $4(13.3)$ & & \\
\hline \multicolumn{5}{|l|}{ Smoking Status ${ }^{\mathrm{a}}$} \\
\hline Non-Smoker & 25(83.3) & $23(76.7)$ & \multirow{3}{*}{$\begin{array}{c}0.202 \\
\left(0.096^{*}\right)\end{array}$} & \multirow{3}{*}{ NS } \\
\hline Active Smoker & $0(0.0)$ & $3(10.0)$ & & \\
\hline Passive Smoker & 5 (16.7) & 4 (13.3) & & \\
\hline \multicolumn{5}{|c|}{ Co-morbid Conditions: n (\%) } \\
\hline Hypertension & $2(6.7)$ & $2(6.7)$ & \multirow{4}{*}{0.642} & \multirow{4}{*}{ NS } \\
\hline Diabetes & $4(13.3)$ & $2(6.7)$ & & \\
\hline Sinusitis & $4(13.3)$ & $1(3.3)$ & & \\
\hline Obesity & $15(50.0)$ & $4(13.3)$ & & \\
\hline
\end{tabular}

Data are expressed as n (\%) or mean (range) unless otherwise indicated, N: number; SD: standard deviation, ${ }^{\mathrm{a} C h i-S q u a r e}$ test at level of significance p $\leq 0.05,{ }^{b}$ Independent t-test at level of significance $\mathrm{p} \leq 0.05$, Sig.: Statistical Significance, S: Significant, NS: Not Significant, ${ }^{\$}$ succeeded any type of higher education (college or university), ${ }^{*}$ p-value when excluding zero cells. 
Table 2. Clinical characteristics for patients participating in the study at baseline.

\begin{tabular}{|c|c|c|c|c|}
\hline Variable & $\begin{array}{l}\text { Intervention Group } \\
\qquad \mathrm{n}=30\end{array}$ & $\begin{array}{l}\text { Routine Care Group } \\
\mathrm{n}=30\end{array}$ & $\mathrm{p}$-value & Sig. \\
\hline ACQ-Score mean \pm SD (range) ${ }^{\mathrm{a}}$ & $2.98 \pm 1.23(1.0-5.7)$ & $3.40 \pm 1.09(1.3-5.6)$ & 0.164 & NS \\
\hline FEV1 \% mean \pm SD (range) $^{\mathrm{a}}$ & $77.63 \pm 21.37(35-100)$ & $64.93 \pm 19.85(31-98)$ & 0.016 & $\mathrm{~S}$ \\
\hline $\begin{array}{l}\text { Rescue Medication SABA average number of } \\
\text { puffs used most days: geometric mean (range) }\end{array}$ & $3.53(0-18)$ & $4.63(0-18)$ & 0.707 & NS \\
\hline $\begin{array}{l}\text { Controller Medication: } \mathbf{n}(\mathbf{\%})^{\mathbf{b}} \\
\text { ICS } \\
\text { LABA } \\
\text { ICS + LABA Combined } \\
\text { Theophylline } \\
\text { Leukotriene modifier }\end{array}$ & $\begin{array}{c}29(96.67) \\
0(0.00) \\
1(3.33) \\
16(53.33) \\
4(13.33)\end{array}$ & $\begin{array}{c}25(83.33) \\
2(6.67) \\
2(6.67) \\
11(36.67) \\
3(10.00)\end{array}$ & 0.527 & NS \\
\hline Mean Daily Dose of ICS average puffs (range) ${ }^{b}$ & $5.9(2-12)$ & $4.6(0-12)$ & 0.13 & NS \\
\hline $\begin{array}{l}\text { Inhalation Technique: } \\
\% \text { Correct Steps mean } \pm \mathrm{SD}^{\mathrm{a}} \\
\text { Patients Scoring } 100 \%^{\mathbf{b}} \\
\text { Patients Scoring } 0 \% \mathbf{b}\end{array}$ & $\begin{array}{c}67.9 \pm 26.8 \\
6.6 \\
6.6 \\
\end{array}$ & $\begin{array}{c}67.9 \pm 25.6 \\
6.6 \\
6.6 \\
\end{array}$ & 0.897 & NS \\
\hline
\end{tabular}

Data is expressed as n (\%) or mean (range) unless otherwise indicated. N: number, SD: standard deviation. ${ }^{\mathrm{a}}$ Independent t-test at level of significance $\mathrm{p} \leq 0.05$, ${ }^{6}$ Chi-Square test at level of significance $\mathrm{p} \leq 0.05$; Sig. Statistical Significance, S: Significant, NS: Not Significant. ACQ: Asthma Control Questionnaire, FEV1: Forced Expiratory Volume in 1second, SABA: Short-Acting Beta2 Agonist, ICS: Inhaled Corticosteroid, LABA: Long-Acting Beta2 Agonist.

Table 3. Clinical characteristics for patients completed the study.

\begin{tabular}{|c|c|c|c|c|}
\hline Variable & $\begin{array}{l}\text { Intervention Group } \\
\mathrm{n}=30\end{array}$ & $\begin{array}{c}\text { Routine Care Group } \\
\mathrm{n}=30\end{array}$ & p-value & Sig. \\
\hline ACQ-Score mean \pm SD (range) $^{\mathrm{a}}$ & $0.93 \pm 0.81(0.14-4.4)$ & $2.47 \pm 0.88(0.71-4.7)$ & 0.0001 & $\mathrm{~S}$ \\
\hline ACQ-dC median (percentiles) ${ }^{\mathrm{b}}$ & $-0.77(-0.60--0.80)$ & $-0.24(-0.13--0.37)$ & 0.0001 & $\mathrm{~S}$ \\
\hline FEV1 \% mean \pm SD (range) $^{\mathrm{a}}$ & $86.07 \pm 19.17(30-100)$ & $71.8 \pm 19.16(23-100)$ & 0.002 & $\mathrm{~S}$ \\
\hline FEV1 \% dC median (percentile) ${ }^{\mathrm{b}}$ & $0.08(0.23-0)$ & $0.10(0.20-0.035)$ & 0.784 & NS \\
\hline $\begin{array}{l}\text { Rescue Medication SABA average number of } \\
\text { puffs used most days: geometric mean (range) }{ }^{c}\end{array}$ & $0.86(0-6)$ & $3.16(0-8)$ & 0.0001 & $\mathrm{~S}$ \\
\hline Mean Daily Dose of ICS average puffs (range) ${ }^{c}$ & $4.2(0-6)$ & $4.2(0-8)$ & 0.854 & NS \\
\hline $\begin{array}{l}\text { ER Visits \& Hospitalization: geometric } \\
\text { mean (range) }{ }^{c}\end{array}$ & $0.2(0-1)$ & $0.73(0-3)$ & 0.013 & $\mathrm{~S}$ \\
\hline $\begin{array}{l}\text { Number of Courses of Systemic Steroid } \\
\text { Used: geometric mean (range) }{ }^{c}\end{array}$ & $0.37(0-2)$ & $0.73(0-3)$ & 0.239 & NS \\
\hline Patients Achieved Asthma Control: $n(\%)^{c}$ & $21(70)$ & $1(3.33)$ & 0.0001 & $\mathrm{~S}$ \\
\hline $\begin{array}{l}\text { Inhalation Technique: } \\
\% \text { Correct Stepsmean } \pm \mathrm{SD}^{\mathrm{a}} \\
\text { Patients Scoring } 100 \%^{\mathrm{c}} \\
\text { Patients Scoring } 0 \%^{\mathrm{c}}\end{array}$ & $\begin{array}{c}92.5 \pm 10.7 \\
60 \\
0\end{array}$ & $\begin{array}{c}75.8 \pm 24.3 \\
10 \\
6.6\end{array}$ & $\begin{array}{l}0.001 \\
0.0049\end{array}$ & $\mathrm{~S}$ \\
\hline $\begin{array}{l}\text { Patient Adherence to Medication (n \%) } \\
\text { Adherent } \\
\text { Non-adherent }\end{array}$ & $\begin{array}{l}90 \\
10\end{array}$ & $\begin{array}{l}66.7 \\
33.3\end{array}$ & 0.028 & $\mathrm{~S}$ \\
\hline
\end{tabular}

Data is expressed as n (\%) or mean (range) unless otherwise indicated. N: number, SD: standard deviation. ${ }^{\mathrm{a}}$ Independent t-test at level of significance $\mathrm{p} \leq 0.05$; ${ }^{\mathrm{b}}$ Wilcoxon Rank Sum test at level of significance $\mathrm{p} \leq 0.05$; ${ }^{\mathrm{C}}$ Chi-Square test at level of significance $\mathrm{p} \leq 0.05$; Sig. Statistical Significance; S: Significant; NS: Not Significant.ACQ: Asthma Control Questionnaire; FEV1: Forced Expiratory Volume in 1second; dC: delta Change calculated as (final value - initial value)/initial value; SABA: Short-Acting Beta2 Agonist, ICS: Inhaled Corticosteroid; ER: Emergency Room; ${ }^{\#}$ patient adherence was assed based on prescription refill rate then patients were categorized as adherent $(\geq 65 \%)$ or non-adherent to medication $(<65 \%)$.

up. As primary outcome of interest, the change in ACQ score from baseline to end of a 2-month follow-up was assessed. The delta change in ACQ-score was of greater magnitude (median: -0.77) in the intervention group compared to routine care (median: -0.243 ) with statistical and clinical significance. The delta change in FEV1 showed no statistically significant difference. Other outcomes such as ER-Visits/Hospitalizations and $\beta 2$-Agonist use after a 2-month follow-up were significantly different. No significant difference in inhaled corticosteroid use was observed between intervention and routine care groups. 


\subsection{Adherence to Controller Medication}

Adherence during the course of the study was assessed using prescription refill rates. $65 \%$ adherence rate was considered as satisfactory to be grouped in adherent category while adherence rate less than $65 \%$ was grouped as non-adherent. Adherence to controller medication was about $20 \%$ higher in the intervention group compared with routine care group.

\subsection{Inhalation Technique}

Inhalation technique was scored using a checklist (eight-point checklist for metered dose inhalers (MDI) and eight-point checklist for dry powder inhaler (DPI)) at the start of intervention and 2 months later. For each correct step, one point was assigned and the sum score was displayed as percentage of correct steps. Patients committing major errors in inhalation technique (for MDI, failure to remove cap and/or fail to shake MDI; for DPI, failure to load device and/ or fail to inhale quickly and deeply through device) were assigned a sum score of zero. For ethical reasons, such major errors were corrected in patients belonging to routine care group.

At baseline, both groups were well-matched showing a mean percentage of correct steps of about $70 \%$. At the end of follow-up, this percentage was significantly higher in the intervention arm $(p=0.0001)$. The percentage of patients performed proper inhalation technique increased by about $50 \%$ in the pharmacist intervention group and by less than $10 \%$ in the routine care group. For patients assigned to the pharmacist intervention, major inhalation technique errors were reduced from $6.6 \%$ to $0.0 \%$ at the end of the study. For patients receiving routine care, these percentages were $6.6 \%$ (at the start of the study) and remained $6.6 \%$ (at the end of the study).

\section{Discussion}

In the current study, the pharmacist intervention was tailored to the patient's current asthma control. By the end of the study, intervention patients who received a written action plan significantly improved their asthma control questionnaire results than routine care group who did not receive a plan. The intervention patients significantly improved both the inhalation technique and medication adherence, which are both key stones for successful asthma management. Together with reduced use of reliever medication, it seems likely that these clinical improvements result from the more appropriate use of the asthma controller medication. Further assessment of inhalation technique steps showed that the most common errors encountered at baseline were incomplete breathout all the way, failure to hold breath for 10 seconds after inhalation and repeated inhalation steps for multiple puffs without wait 1-minute in-between. These errors were significantly reduced in the pharmacist intervention group where patients showed better outcomes.

In the present study, almost all patients were prescribed inhaled corticosteroids as controller treatment. Patients in the intervention arm were $20 \%$ more adherent than patients receiving usual care, suggesting a beneficial impact intervention.

This study was performed based on shared decision making i.e. patients were allowed to negotiate treatment regimens that accommodate their goals and preferences. Applying shared decision making, patient concerns about asthma and asthma treatment were addressed, treatment goals were developed together with patient and self-management of asthma was encouraged.

Regarding controller medication use, both inhaled and systemic corticosteroid showed no significant difference between the intervention and routine care groups. However, intervention patients experience less asthma exacerbations with decreased need for emergency department visits and/ hospitalization than routine care patients. This suggests that the improvement in symptom control seen in the intervention group can be attributed to the extra pharmacist care and not to changes in pharmacotherapy.

Charrois and colleagues conducted a similar study in Alberta, Canada (Edson and Hinton) that showed no differences in asthma control [18]. However they mentioned that many intervention group patients did not receive an action plan, or education about their action plans at each visit. Also, completeness of follow-up was poor with, less than two-thirds of patients completing the 6-month follow-up [18].

Mehuys and colleagues conducted another study in Belgium. Patients were randomly assigned to receive usual pharmacist care or a pre-defined pharmacist intervention. This intervention mainly focused on improving inhalation technique and medication adherence. Primary outcome was the level of asthma control, as assessed by as primary outcome of interest, the mean Asthma Control Test (ACT) scores did not change from baseline for 
both study groups. However, a pre-defined subgroup analysis of patients having insufficiently controlled asthma at baseline showed that the intervention had significantly increased the ACT score after 6 months compared with usual care. The intervention also reduced, for the complete study group, reliever medication use and the frequency of night-time awakenings due to asthma. Inhalation technique and adherence to controller medication were significantly better in the intervention group [5].

Our study results are consistent with findings from another study performed by Armour and colleagues. A pragmatic cluster randomized trial in community pharmacies in Australia in 2009 to test the feasibility, effectiveness, and sustainability of a pharmacy asthma service. Poorly controlled asthma patients were followed-up for 12 months after asthma care service provided by specially trained pharmacist. Patient showed improvement in asthma control as evident by ACQ-scores, inhaler technique and asthma action plan ownership [19].

Wilson and colleagues performed a study where they applied shared decision making strategy and reported that negotiating patients' treatment decisions significantly improved adherence to asthma pharmacotherapy and clinical outcomes [20]. Patient education and asthma self-management are expected to be extensively searched as patient care strategies to improve asthma control and identify barriers to achieve and maintain better control of asthma.

Worth-mentioning, the previously mentioned studies was conducted in different countries that may differ in health care systems and pharmacy practice issues. Furthermore, studies differed in their design, outcomes, and measurement. Therefore, Transferability of findings needs to be carefully considered and more research is expected to evaluate different implementations of care plans in different settings.

\section{Conclusion}

The present study results provide supportive evidence concerning pharmacists' favorable effects on asthma patient care and supports pharmacists as key members of the health care team.

\section{Study Limitations}

The present study has its limitations. First, the number of patients participated in the study was relatively small compared to other large multicenter studies investigating asthma self-management programs. However, this can be explained by time and funding constraints. Moreover, the number of subjects selected is consistent with number needed to treat (NNT) for optimal self-management program based on Cochrane reviews [21]. Second, patients participated voluntarily in the study. Therefore, the selected sample may reflect those patients with a stronger interest in self-management, possibly generating a positive selection bias. Third, the present study was an open-label study as the intervention necessitates patient education. Fourth, the sustainability of beneficial outcomes beyond two months was not assessed.

\section{Acknowledgements}

Thanks to Dr. Mohsen Fathallah, executive manager of Genuine Research Center, for statistical advice. We would like to thankall staff members and allied health team at Ain Shams University Hospitals, Cairo, Egypt for their cooperation.

\section{References}

[1] Lougheed, M., Lemiere, C., Dell, S. and Ducharme, F.J. (2010) Canadian Thoracic Society Asthma Management Continuum-2010 Consensus Summary for Children 6 Years and over and Adults. Canadian Respiratory Journal, 17, 1530.

[2] Anandan, C., Nurmatov, U., VanSchayck, O. and Sheikh, A. (2010) Is the Prevalence of Asthma Declining? Systematic Review of Epidemiological Studies. Allergy, 65, 152-167. http://dx.doi.org/10.1111/j.1398-9995.2009.02244.x

[3] World Health Organization (2011) WHO Media Center, Asthma Fact Sheet No. 307. http://www.who.int/mediacentre/factsheets/fs307/en/\#

[4] Rabe, K., Adachi, M., Lai, C., Soriano, J., Vermeire, P., Weiss, K., et al. (2004) Worldwide Severity and Control of Asthma in Children and Adults: The Global Asthma Insights and Reality Surveys. Journal of Allergy and Clinical Immunology, 114, 40-47. http://dx.doi.org/10.1016/j.jaci.2004.04.042

[5] Mehuys, E., Van Bortel, L., De Bolle, L., Van Tongelen, I., Annemans, L.R. and Brusselle, G. (2008) Effectiveness of 
Pharmacist Intervention for Asthma Control Improvement. European Respiratory Journal, 31, 790-799. http://dx.doi.org/10.1183/09031936.00112007

[6] Salama, A., Mohamed, A., El-okda, E. and Said, R. (2010) Quality of Care of Egyptian Asthmatic Children: Clinicians Adherence to Asthma Guidelines. Italian Journal of Pediatrics, 36, 33. http://dx.doi.org/10.1186/1824-7288-36-33

[7] Global Initiative for Asthma (2012) Global Strategy for Asthma Management and Prevention. http://www.ginasthma.org/local/uploads/files/GINA_Report_March13.pdf

[8] National Institute of Health; National Heart, Lung, and Blood Institute; National Asthma Education and Prevention Program (2007) Expet Panel Report 3: Guidelines for the Diagnosis and Management of Asthma. http://www.nhlbi.nih.gov/guidelines/asthma/

[9] Bateman, E., Reddel, H., Eriksson, G., Peterson, S., Ostlund, O., Sears, M., et al. (2010) Overall Asthma Control: The Relationship between Current Control and Future Risk. Journal of Allergy and Clinical Immunology, 125, 600-608. http://dx.doi.org/10.1016/j.jaci.2009.11.033

[10] Bai, T., Vonk, J., Postma, D. and Boezen, H. (2007) Severe Exacerbations Predict Excess Lung Function Decline in Asthma. European Respiratory Journal, 30, 452-456. http://dx.doi.org/10.1183/09031936.00165106

[11] Boulet, L. (2011) Asthma Control, Education, and the Role of the Respiratory Therapist. Canadian Journal of Respiratory Therapy, $\mathbf{4 7}, 15-20$.

[12] Laforest, L., VanGanse, E., Devouassoux, G.B., Chretin, S., Baguail, G., Pacheco, Y., et al. (2006) Influence of Patients' Characteristics and Disease Management on Asthma Control. Journal of Allergy and Clinical Immunology, 117, 1404-1410. http://dx.doi.org/10.1016/j.jaci.2006.03.007

[13] Balter, M., Bell, A., Kaplen, A., Kim, H. and McIvor, R. (2009) Management of Asthma in Adults. Canadian Medical Association Journal, 181, 915-922. http://dx.doi.org/10.1503/cmaj.080007

[14] British Thoracic Society and Scottish Intercollegiate Guidelines Network (2012) British Guideline on the Management of Asthma. http://www.brit-thoracic.org.uk/Portals/0/Guidelines/AsthmaGuidelines/sign101\%20Jan\%202012.pdf

[15] World Medical Association General Assembly. WMA Declaration of Helsinki-Ethical Principles for Medical Research Involving Human Subjects. http://www.wma.net/en/30publications/10policies/b3/

[16] Juniper, E.F., O’byrne, P.M., Guyatt, G.H., Ferrie, P.J. and King, D.R. (1999) Development and Validation of a Questionnaire to Measure Asthma Control. The European Respiratory Journal, 14, 902-907. http://dx.doi.org/10.1034/j.1399-3003.1999.14d29.x

[17] Sveum, R., Bergstrom, J., Brottman, G., Hanson, M., Heiman, M., Johns, K., et al. (2012) Diagnosis and Management of Asthma.

https://www.icsi.org/guidelines_more/catalog_guidelines_and_more/catalog_guidelines/catalog_respiratory_guideline s/asthma/

[18] Charrois, T.L., Newman, S.C., Senthilselvan, A. and Tsuyuki, R.T. (2006) Improving Asthma Control in the Rural Setting: The BREATHE (Better Respiratory Education and Asthma Treatment in Hinton and Edson) Study. Canadian Pharmacist Journal, 139, 44-50. http://dx.doi.org/10.1177/171516350613900410

[19] Armour, C.L., Reddel, H.K., LeMay, K.S., Saini, B., Smith, L.D., Bosnic-Anticevich, S.Z., et al. (2013) Feasibility and Effectiveness of an Evidence-Based Asthma Service in Australian Community Pharmacies: A Pragmatic Cluster Randomized Trial. Journal of Asthma, 50, 302-309. http://dx.doi.org/10.3109/02770903.2012.754463

[20] Wilson, S., Strub, P., Buist, A., Knowles, S., Lavori, P., Lapidus, J., et al. (2010) Shared Treatment Decision Making Improves Adherence and Outcomes in Poorly Controlled Asthma. American Journal of Respiratory and Critical Care Medicine, 181, 566-577. http://dx.doi.org/10.1164/rccm.200906-0907OC

[21] Gibson, P.G., Ram, F.S. and Powell, H. (2003) Asthma Education. Respiratory Medicine, 97, 1036-1044. http://dx.doi.org/10.1016/S0954-6111(03)00134-3 


\section{Abbreviations Note List}

ACQ: Asthma Control Questionnaire

ACT: Asthma Control Test

COPD: Chronic Obstructive Pulmonary Disease

DPI: Dry Powder Inhaler

ER Visit: Emergency Room Visit Related to Asthma

FEV1: Forced Expiratory Volume in 1 Second

GINA: Global Initiative for Asthma

IBM Corp: International Business Machine Corporation

ICS: Inhaled Corticosteroid

LABA: Long-Acting Beta2-Agonist

MDI: Metered-Dose Inhaler

NNT: Number Needed to Treat

SABA: Short-Acting Beta2-Agonist

SPSS: Statistical Package for the Social Sciences 